\title{
ESCRITURA, ESPACIO, ARQUITECTURA: UNA TIPOLOGÍA DEL ESPACIO LITERARIO ${ }^{1}$
}

\author{
Jesús Camarero
}

(Universidad del País Vasco)

Trabajar sobre el espacio implica una reflexión permanente sobre las maneras diferentes como se presenta y representa ese espacio, porque una realidad o un texto provocan al menos una interrogación nueva que no cesa de interrogar a su vez de modo fascinante a todo aquel que escribe, lee o contempla el mundo con una visión inteligente. Así, trabajar sobre el espacio implica ante todo hacer el espacio, es decir, ser conscientes de la dimensión espacial de nuestra existencia. Pero, ¿qué es el espacio? Georges Perec, en su libro Espèces d'espaces nos facilita algunas definiciones. Una primera definición concierne el trabajo del ojo, de la mirada, es decir, la actividad de la percepción, del trabajo intelectual de base: «Utilizamos nuestros ojos para ver. Nuestro campo visual nos desvela un espacio limitado» (1974a: 109). Luego realiza una aproximación a la dicotomía funcional sujeto/objeto

1 Texto basado en el seminario que fue impartido el 13 de junio de 1992 en la Bibliothèque Pierre Albouy, E.U.R. des Sciences des Textes et Documents, Université de Paris VII-Jussieu. 
de esta percepción cuando el hombre piensa ese espacio percibido: «Nuestra mirada recorre el espacio y nos da la ilusión del relieve y de la distancia. Así construimos el espacio: con un arriba y un abajo, una izquierda y una derecha, un delante y un detrás, un cerca y un lejos. [...] El espacio es lo que frena la mirada, es aquello con lo que choca la vista» (ib. ant.). Y también: «el espacio es una duda: tengo que delimitarlo sin cesar, lo tengo que designar, nunca me pertenece, nunca se me otorga, tengo que conquistarlo yo» (1974a: 122). El espacio puede ser un objeto pero también un fenómeno, puede ser percibido pero también re-construido o representado. En todo caso se trata siempre de aquello que es cercano al hombre, la cosa primera, el lugar del origen, del destino y de la actividad del hombre. Cuando del espacio se trata, las primeras ideas que vienen a la memoria son la abstracción, la inmensidad, el infinito... Pero el hombre se ha acostumbrado a concretar esas ideas vagas y peligrosas en muchas ideas asociadas a su existencia y, aquí, una vez más, Espèces d'espaces constituye el catálogo de esas ideas concretas perfectamente clasificadas, explicadas y transformadas ellas mismas en espacio de la escritura. El espacio constituye la materia que la actividad incansable del hombre transforma sin cesar. Antes era el espacio, después es el espacio también, y no el espacio de antes, sino otro que ya no es el primero. La transformación del espacio da sentido a la existencia humana, sin el espacio no hay vida... y Perec lo había entendido perfectamente al escribir La Vida instrucciones de uso. Pero el espacio no es la única figura que podría servir para explicar las cosas del mundo, también está el tiempo. Una contraposición espacio/tiempo como la que propone G. E. Lessing (1990) en el siglo XVIII no es pertinente ya, porque el espacio y el tiempo van siempre juntos, porque el objeto puede ser aprehendido de dos modos diferentes y complementarios a la vez, porque la yuxtaposición y la linealidad no son categorías estancas y pueden aplicarse a todos los tipos de objeto. Lessing estaba en un error, ya que hay muchos cuadros que cuentan historias (tienen entonces una dimensión temporal) y hay muchos poemas, como Un coup de Dés... de Mallarmé, o Alphabets, de Perec, cuya singular disposición espacial organiza la significación del texto. No se puede percibir el tiempo, lo que se percibe es el espacio. La instantaneidad del espacio nos permite acercarnos a los objetos que contiene, es la evidencia, lo real, la posibilidad de la referencia, el acto de la representación. El tiempo pasa y desaparece sin parar (por ejemplo los segundos transcurridos desde el comienzo de este párrafo ya no volverán jamás); por el contrario, el espacio atrae al espacio, un espacio es siempre el comienzo de una dimensión en que otros espacios son posibles, el espacio crece a medida que se transfor- 
ma y las cosas contenidas en él no se agotan jamás, pues su materia no tiene ni principio ni fin. El espacio es lo que se puede percibir: materia, referencia, elemento, indicio,... Todo lo que es susceptible de ser modificado por una actividad, todo lo que se presta a la transformación operada por la energía del saber-hacer humano. Cuando del espacio se trata, también es cuestión de la creación: un fenómeno que se produce siempre a partir de algo cuya materia permitirá una acción. Y la percepción implica lo visual, porque el ojo es el instrumento más importante para la percepción - la mayoría de la información que recibimos viene por los ojos- y la mirada, la acción que implica la vista, porque los modos de esa mirada son ya una forma que cuenta para el producto final de la percepción. Después habrá que decir el objeto percibido anteriormente. Pero cuando se dice el objeto del mundo que es el espacio o que ocupa el espacio, el objeto ya no está allí y el espacio tampoco. Decir el objeto del espacio ya no es ese espacio, salvo para la escritura que se escribe sobre el espacio de la página y que construye otro espacio artificial incorporando una teoría del signo y de la significación. Escribir es hacer el espacio, porque el texto se hace también objeto: ocupa un lugar, una dimensión, es un volumen, es objeto de una percepción, de una lectura, es comprendido y puede ser transformado o reescrito. Primero está la página blanca que delimita un espacio virgen pero significante, ya que el vacío cuenta también para el balance escritural (piénsese en el Coup de Dés mallarmeano o en el Passage de Milan butoriano). Luego está el conjunto de signos de la escritura que se inscriben sobre la página y en la página. Si los signos significan porque hay un código preestablecido y una significación arbitraria, la disposición u organización de esos signos sobre la página también adquiere significado. He aquí pues otro tipo de espacio significante y artístico tal como lo había definido Yuri M. Lotman (1982: 270-271) en la idea siguiente: «la estructura del espacio del texto se convierte en modelo de la estructura del espacio del universo, y la sintagmática de los elementos en el interior del texto, en el lenguaje de modelización espacial».

La noción del espacio del texto con una disposición del soporte y de los signos es, quizá, un invento de Mallarmé. Después vinieron Apollinair y sus Calligrammes, Raymond Queneau y sus Cent mille milliards de poèmes, la poesía espacial, el Inismo... Pero también está Perec con el conjunto de su poesía heterogramática (Alphabets, Ulcérations, La Clôture, Métaux), donde la fórmula permutacional de una secuencia de signos (por ejemplo: E-S-A-R-T-I-N-U-L-O) permite desarrollar configuraciones textuales absolutamente legibles, com- 
prensibles y significantes, una especie de reinvención del lenguaje y del lenguaje poético. Igual que la reinvención de la escritura del relato en La Vie mode d'emploi: toda una maquinaria de constricciones relacionadas unas con otras construye las novelas de una estructura perfecta en la que el autor ha previsto todos los movimientos de ocupación y organización, una representación del espacio del mundo por medio de un espacio narrativo. Sin olvidar Espèces d'espaces, donde se podrá encontrar de modo explícito una teoría general del espacio humano contemporáneo y, también, un libro de los espacios diferentes de nuestra civilización, cuya organización jerárquica se justifica por las dimensiones que ocupan en el conjunto infinito de un espacio desconocido. La calle sería el nivel número seis de esta clasificación que va de la página al mundo. Su definición es la siguiente: «... la calle es un espacio [...] bordeado por casas» (1974a: 65). Al final del capítulo, el trabajo en curso del escritor concierne La rue Vilin: «sentado en un café o andando por la calle, con un cuaderno y una pluma en la mano, me esfuerzo en describir las casas, las tiendas, la gente que se cruza conmigo, los carteles y, en general, todos los detalles que atraen mi mirada" (1977: 2). Se trata de la ciudad, del barrio, de la calle... Los lugares de la actividad del hombre que transforma el espacio, los objetos, el mundo. Entonces, si el lugar de la calle pasa a un texto que es un signo, hay que tener en cuenta al menos tres niveles de este fenómeno de representación:

1) La calle Vilin, el lugar parisiense visitado por Perec, una entidad física, urbanística y arquitectónica, un objeto para la percepción del escritor, una realidad de tres dimensiones susceptible de ser percibida y de convertirse luego en objeto artístico, es el espacio del referente.

2) Un texto que se llama también La rue Vilin (la cursiva marca la distancia respecto del objeto), un conjunto de signos acumulados en un texto de dos dimensiones, un gran signo que representa ese objeto durante un tiempo que va desde el 27 de febrero de 1969 hasta el 27 de septiembre de 1975, un espacio que se transforma y cuya transformación es percibida en un lapso temporal, es el espacio del significante.

3) La historia velada de una vida, sin dimensión, que constituye otro fragmento de la autobiografía perecquiana, la degradación y la desaparición de una calle donde Perec vivió, el recuerdo que ya no es la existencia, es el espacio del significado.

Éste es el signo espacial que resume el texto de Perec, un signo de la escritura (espacio de dos dimensiones) que representa otro espacio 
vivido (de tres dimensiones). Desde este punto de vista La rue Vilin es un homenaje al espacio, hay una especie de funcionamiento pictórico: la escritura se hace pincel de la representación. Además la calle Vilin, entidad urbanística y arquitectónica, no existe ya; pero ese espacio no ha desaparecido del todo, sino que es un espacio transformado por la acción del hombre que reconstruye las ciudades sin cesar; y, paradójicamente, lo que queda de un modo más firme y permanente es su representación: un texto que se llama La rue Vilin, una película que se titula En remontant la rue Vilin (de Robert Bober) y otros textos que representan ese texto o esa película. Es decir, los signos que re-presentan el espacio primero del mundo real o ficticio. De este modo, a través de los signos, la permanencia del objeto está asegurada.

\section{EL ESPACIO DEL OBJETO}

Es el espacio del referente, del mundo exterior, lo que nos rodea, el dominio de la existencia humana, donde la literatura y el arte en general podrían encontrar la fuente de su inspiración; pero el objeto de este espacio no es totalmente literario, no pertenece a la esencia de la literariedad porque es el objeto de las ciencias puras y, sobre todo, porque está siempre ausente del texto y sólo se da indirectamente, por medio de otra cosa que no es ese objeto (el signo que es el texto). Este espacio referencial constituye, según Bollnow, «la manifestación de la vida humana concreta» (1969: 25), no es algo psíquico, sino lo real vivido o viviéndose, el mundo tangible cuya materia es el objeto de la actividad del hombre; se trata pues de la relación implícita del individuo y del entorno, que a veces pasa a la literatura, bien sea representando al hombre que transforma el espacio de su existencia, bien sea imitando el espacio mismo que determina a veces la acción del hombre. Es la vida del escritor relacionada con el mundo que contiene los objetos bajo la forma acumulativa y proliferante de nuestra contemporaneidad; lo cual provoca algunas patologías en este tipo de espacio, como en la historia bastante explícita de Les Choses: esta permanencia agobiante de los objetos determina y modifica la presencia y la acción de los personajes en la novela, un conflicto que se resuelve con la sumisión del sujeto al objeto (Jérôme y Sylvie son dos personajes sin carácter y su presencia se justifica más por el amontonamiento material que ellos ansían poseer que por su decir o su hacer). 
La arquitectura es la ciencia del espacio. Un arquitecto diseña los espacios que contendrán los objetos, las personas, la vida. Según R. Bofill, ser arquitecto significa comprender el espacio organizado del hombre y la arquitectura es ese lugar de una teoría en que la vida del hombre queda ligada a los objetos del mundo, susceptibles de ser representados o referidos por los signos del arte o la literatura, una alusión al objeto que es una cosa diferente del objeto mismo. El texto de La rue Vilin cuenta una descripción de esta calle del $20^{\circ}$ distrito parisiense a comienzos de 1970 . Entonces este texto representa un objeto determinado del espacio: el objeto espacial de una calle, de un barrio, de una ciudad. El espacio del texto sirve para dibujar, reproducir, incluso simular el espacio real de ese lugar parisiense; pero el objeto no está en el texto, no es el texto, ya que el texto es su signo y sustituye a la calle. En La rue Vilin el texto se hace el espacio de una descripción y, al mismo tiempo, esta descripción es la descripción del espacio urbano, urbanístico y arquitectónico de esa calle. Además, las características del texto de La rue Vilin están muy en la línea de la obra de Perec. La proliferación y la acumulación de objetos (casas, comercios, pocas personas) es absolutamente normal si tenemos en cuenta otros textos como Les Choses, las «tentatives d'épuisement»o La Vie mode d'emploi, y la enumeración del conjunto se hace por las palabras, por los significantes del texto con función denotativa subrayada, como diciendo: «esto no es una calle» (Magritte sería tajante en este caso).

La escritura no es solamente el espacio de la representación, o no tanto, sino sobre todo la representación del espacio: lo que hay que poner de relieve no es la forma espacial de la escritura (que luego se verá), sino sobre todo su función tradicional, ya que representa algo antes de representarse a sí misma, y lo que representa es el espacio de lo exterior y el espacio arquitectónico. Se trata pues de una escritura transitiva que denota un «complemento de objeto directo» saturado por su función mimética abusiva. Esta descripción detallada de la minucia no es algo gratuito y sus implicaciones llegarán hasta el espacio del significado. De entrada está la anécdota de la mesa de relojero sobre la que trabajaba Perec, un tipo de mesa bastante pertinente para el trabajo con muchos objetos casi insignificantes por su dimensión, pero absolutamente importantes para el funcionamiento de la maquinaria.

Una escritura con función tradicional representativa exige un tipo de lectura lineal en principio, pero esta constricción de la descodificación textual no es la única posibilidad de acceso al universo represen- 
tado. Es posible, por ejemplo, elaborar un recorrido diferente por el repertorio descriptivo disponiendo verticalmente los elementos de la descripción de cada visita, para obtener seis listas autónomas y verticales que se pueden leer transversalmente para verificar, número a número de la calle, la transformación sufrida a partir de la segunda visita. De este modo la linealidad impuesta por las visitas sucesivas que produce seis estados diferentes y consecutivos del lugar, se convierte en una co-presencia de seis listas simultáneas, instantáneas cuya lectura tabular, y no ya lineal, permitiría la comprensión de la esctructura taxonómica del relato, así como el proceso de degradación del que hablaremos después. La lectura tabular permite el consumo feliz del conjunto taxonómico en esta descripción exhaustiva de la desaparición de una calle. Y dentro de ese conjunto están, por ejemplo, los componentes del mundo sensible: los colores (el azul de la lavandería de fachada deslavazada, el azul cielo y amarillo de la fachada de un comercio, el rojo de las paredes, el amarillo de la casa del $n .^{\circ} 49$, el velomotor abigarrado, el ocre de una panadería) y los sonidos (música de jazz, música árabe, un ruido de máquina de coser). Pero la lectura tabular permite ante todo la representación perfecta del objeto arquitectónico: los elementos de la construcción, la disposición de esos elementos, el cuidado de las casas; es decir, el relato de una historia arquitectónica de la calle Vilin del $200^{\circ}$ distrito parisiense.

El fenómeno que marca sin duda alguna la lectura de este texto es el aspecto material de la descripción, tanto en su versión positiva como negativa. Desde el punto de vista positivo tenemos los siguientes componentes: el proceso de construcción de los «HLM» en la calle Couronnes, el revestimiento de fachadas (sobre todo al principio de la calle), la reconstrucción de una casa en el $\mathbf{n} .^{\circ} 12$ o de un comercio en el $n .^{\circ}$, las expresiones que delatan un estado determinado («toujours intact», «toujours là», «toujours debout»). Y en el lado negativo: el deterioro de las casas (sinónimo de degradación), el carácter «destripado» de los n. ${ }^{\text {os }} 23$ y 25 , las expresiones «plus rien», «la rue s'arrête ici», «rien au-delà»; el carácter «demolido» o «destruido» constatados en la visita de 1972 se convierte en «empalizadas» y «solares» en 1974. La transformación del espacio arquitectónico implica a veces el vaciado de la calle; lo que queda es el indicio de una presencia anterior (la empalizada, por ejemplo) que a su vez se hace signo. Y hay también una cierta historia de «comercios cerrados». En su primera visita al barrio, el n. 1 de la calle lleva ya la inscripción de «cerrado» y «todavía no ha encendido las luces»; la cerrazón y la oscuridad muestran la ausencia bien de vida, bien de actividad, y ello constituye el retrato 
hiperrealista realizado a partir de una experiencia visual intensa que, además, se continúa a lo largo de todo el relato: en el $\mathrm{n}^{\circ} 7$ hay también otro comercio cerrado «desde hace tiempo», luego en el $n .^{\circ} 9$, en el 11 , en el 16, en el 22 , en el 24 (por supuesto, ya que se trata del comercio de su madre, que no ha vuelto a abrirse). Sólo hay un contrapunto, cuando Perec vuelve a las siete de la tarde ya anochecida y obtiene una visión ciertamente diferente del entorno. La visualización de los comercios es más rápida, de una instantaneidad casi pura, como de extrema urgencia: es el ojo que trabaja intensamente y que encuentra su objeto enfrente, absolutamente próximo, sin posibilidad de fuga, un círculo vicioso que se repite sin parar en la vida urbana y que muestra el proceso de producción y desaparición de los barrios y de las casas, la transformación del espacio de la ciudad. La calle se hace cada vez más vieja, los vecinos mueren o se marchan, los comercios ya no son rentables y cierran, las casas y los comercios abandonados se estropean muy deprisa, finalmente llega la expropiación forzosa. Estos son los avatares del espacio referencial tal como ha sido representado por el texto de Perec.

\section{EL ESPACIO DEL TEXTO}

Es el conjunto de signos de la escritura depositados sobre el soporte de otro espacio: la página. Es el espacio ocupado por los significantes, por la materialidad de la escritura inscrita sobre el soporte y las configuraciones ${ }^{2}$ obtenidas en el momento de la inscripción. Es un espacio que tiene en cuenta los signos, bien para imitar la disposición de los objetos en su lugar específico - es la representación-, bien para obtener otras formas cuyo referente podría estar ausente -es la metarrepresentación- (ambos términos son de Jean Ricardou 1987: 5).

El espacio «textual» es una suerte de disposición geográfica de los grafos, el texto es el tejido de una configuración o de una forma, algo material que se puede tocar y manipular. Se trata del juego de la escritura que quisiera reproducir una cierta disposición de lo real para representarlo lo mejor posible. Es la descripción. La escritura desaparece a medida que los edificios desaparecen. Si el espacio-inmueble de

2 A este respecto resulta obligada la consulta del artículo de Enzensberger, donde se perfila claramente el concepto de ciertas estructuras complejas que habitan el territorio interno del texto en este tipo de literatura. 
la arquitectura se degrada, el signo del espacio escritural ya no desciende sobre la página $y$, del mismo modo, la cantidad de espacio construido que queda en pie todavía se corresponde con la cantidad de signos acumulados en el texto; tal es la correspondencia del espacio arquitectónico y del espacio escritural operada por medio de la descripción taxonómica. La taxonomía comporta una forma del texto tal que reproduce un cierto orden de lo real; el orden o clasificación de los componentes del texto se corresponde con el orden percibido del espacio referencial (es la idea de Lotman expuesta anteriormente).

Pero el problema es el paso de las tres dimensiones del espacio referencial a las dos dimensiones del espacio textual o escritural. Según Greimas y Courtés (1979), la taxonomía es «un procedimiento de organización sistemática de los datos observados y descritos»; entonces, si se reproduce el amontonamiento de los objetos contenidos en el espacio de la calle Vilin y se organiza una escritura de catálogo para contar esto, el texto se convierte en una forma de tabulación cuya estructura tabular paradigmática requiere una lectura tabular que funciona verticalmente y que se adapta al efecto de enumeración. La forma tabular produce entonces algunos tipos de configuración de la escritura del texto, unos topoi de la puesta en discurso de una descripción semiótica del espacio arquitectónico que evocan cierta tridimensionalidad:

a) La enumeración taxonómica de todos los edificios y de los comercios constituye una serie de «tablas», donde los significantes se inscriben en secuencias homogéneas del tipo: «au $n .^{\circ} 1$, au $n .^{\circ} 2$, au n. ${ }^{\circ}$...», o «du côté pair, du côté impai...», o «sur la gauche, sur la droite...», o «au fond, en face...».

b) Las seis visitas al lugar son los seis capítulos del texto, es decir, lo temporal del referido produce lo espacial del signo.

c) Del mismo modo, la disposición del texto reproduce la disposición de los edificios: el lado par y el lado impar aparecen alternativamente en la mayoría de los casos.

d) La frase corta, a veces sin verbo, constituye un cierto estilo tabular, una especie de lenguaje telegráfico acompañado de un protagonismo total de lo nominal, de modo que se puedan construir secuencias de fotogramas relacionadas con una cierta memoria.

e) La inscripción especial, de carácter intertextual, de anuncios, cartelitos, rótulos, letreros, «inscripciones», siglas, anuncios oficiales, placas, grafitti, reproducidos todos ellos tal cual, como una cita, constituye 
una especie de catálogo casi autobiográfico de algunos fragmentos que pertenecen al objeto real del espacio referencial.

Lo cual supone una inscripción de los signos de la escritura como una red (de acuerdo con la clasificación precedente) en que las relaciones de intersección (a), adición (b) o alternancia (c) cuentan para la significancia, en que el estilo sustantivo (d) muestra un semantismo subrayado, en que el diálogo con los textos añadidos (e) exige una lectura más allá del texto. Es pues una suerte de metalenguaje, un desvío operado a partir de la lengua, un lenguaje gramatical que describe el objeto que ya no es la lengua misma, sino el conjunto integrado de las operaciones de la significación y de la significancia. Y el resultado sería el fenómeno ricardoliano de la metarrepresentación, pues la representación, que era la función primera de este texto descriptivo, se mezcla con el acontecimiento de la escritura, se une a la manipulación de los componentes escriturales para obtener una significación añadida que tiene en cuenta la forma, que tiene en cuenta el juego de posibilidades de organización del lenguaje y de la escritura, un trabajo sobre la materia escritural que invita al lector a una aventura de interpretación y quizás, por qué no, a una reescritura.

\section{EL ESPACIO DEL SIGNIFICADO}

Es el fruto de la imaginación, de la representación mental: percibimos los objetos de lo real y nos construimos una imagen de ellos; del mismo modo, cuando leemos un texto, la traducción-traición de las palabras por un código de lo arbitrario nos hace representar los objetos referidos por esas palabras. Los objetos están en el espacio de lo real y del mundo, y las palabras están en el espacio del texto y de los volúmenes, pero las ideas elaboradas a partir de esos objetos y de esas palabras constituyen un espacio imaginario o simbólico cuya existencia escapa a nuestra percepción. No podemos tocar las ideas, no leemos las ideas, no las vemos, no las podemos manipular... salvo si se hace por medio de las palabras por ejemplo. Es la presencia de una ausencia (un eco es como una idea y leer es ante todo saber provocar esos «ecos»).

A medida que avanza el relato de La rue Vilin, la degradación de los edificios se va convirtiendo en el agotamiento de la escritura en su propia materialidad. La sexta visita es demasiado breve, tiene lugar 
de noche - «vers $2 \mathrm{~h}$. du matin»- y su descripción es lacónica, telegráfica. Los signos de la escritura se ausentan de la página del mismo modo como los edificios desaparecen del lugar referencial a causa de la actuación de los obreros encargados de la demolición; a medida que el texto avanza la escritura se hace esquelética, es la agonía del referente, el vacío, la desaparición. Las seis etapas de la degradación de la calle Vilin suponen una especie de evolución metastática de los comercios y de las casas, una visión del espacio como una materia que se transforma sin cesar, el principio heraclitiano que nos habla de una característica esencial del espacio: un espacio que no cambia no es un espacio. El espacio del significado supone el encuentro de la arquitectura y de la escritura, un encuentro autobiográfico que reproduce las imágenes de una memoria cuyos recuerdos están asociados al devenir de una calle. El producto final de esta ocurrencia concierne al escritor y su actividad, concierne la vida y la escritura: el n.o 1 «c'était [...] l'immeuble où vivaient les parents de ma mère»; el 24 es «la maison où je vécus»; la forma de la calle es como dos eses, las siglas de la policía nazi; la mujer del 36 , que se acuerda de la peluquera del $24 .$. Lo que queda es el recuerdo hecho escritura. El espacio del significado es el espacio de la degradación, del deterioro, de la demolición, cuyo único signo es la escritura. Por ello, la escritura que representa el objeto dibuja a veces algunos signos de esta degradación: los muros y las empalizadas son las fronteras del espacio vaciado y suponen el «borramiento» arquitectónico; las ventanas y las puertas clausuradas son el «cegamiento» del edificio abandonado o expropiado y la transformación de la ciudad; la palabra vilin se pronucia [vilê], igual que la palabra vilain (feo, malo, negativo). La significación global de este texto es la imagen o la figura de la degradación. No queda ya ninguna posibilidad de salvar ese espacio material que constituye el objeto de la referencia, pero nos queda la escritura de una historia sobre los últimos días de un fragmento del espacio parisiense donde algunas vidas fueron posibles: las de los vecinos de la calle Vilin y la de Perec mismo.

Según la sentencia de Wittgenstein, «el nombre significa el objeto» (1989: 33), es decir, la organización de signos estructurados por la descripción significa la acumulación organizada de esos elementos arquitectónicos y urbanísticos que componían aquel lugar de la calle Vilin. El espacio vivido, real, de una vida pretérita, ya no está aquí y es remplazado por el espacio textual de la descripción de su recuerdo. La calle Vilin (una pequeña calle de París) es La rue Vilin (el título de un relato ecfrástico), la calle es el texto. De este modo el espacio limitado 
del texto ${ }^{3}$ reproduce el objeto infinito del espacio. Según el matemático Aleksandrov, citado por Lotman (1982: 271), «el espacio es el conjunto de los objetos homogéneos [...] entre los cuales se pueden establecer relaciones como las de las relaciones espaciales corrientes (continuidad, distancia, etc.)». El texto es el modelo del universo porque reproduce su materia al mismo tiempo que la imita y, entonces, las palabras del texto sirven para representar y significar lo que nunca estará en el texto. El núcleo del problema es semántico: la descripción equivale a la representación. Si un objeto descrito obtiene una significación en el interior de la secuencia textual correspondiente es gracias al código de la representación, ya que la alusión a este objeto obliga al sujeto a reproducir su imagen y, de este modo, el sujeto puede apropiarse de algo que antes no le pertenecía. La tabulación del interior del texto reproduce el orden de los elementos en el espacio externo. Pero la escritura no es el espacio total, no es como el espacio de tres dimensiones. En La rue Vilin esta limitación de la escritura (puesto que se hace en las dos dimensiones de la hoja) ha sido compensada por la representación de un espacio de tres dimensiones: el de las casas, los comercios, la calle, el espacio infinito. Es la función de la referencia objetiva: una palabra en relación con un objeto. El texto no es el objeto (Magritte), pero el texto significa los objetos (Wittgenstein). A efectos del fenómeno de la representación, el espacio del significado es secundario porque no añade nada esencial a ese lazo que une la palabra y el objeto. Mientras que hay una relación inmediata entre la palabra y el objeto, el significado exige una traducción del significante que a veces es una traición (piénsese por ejemplo en los problemas de la polisemia o la homonimia) y la relación que Aristóteles había establecido entre los tres términos, objeto-palabra-idea, quizá no sea ya un triángulo sino una pirámide truncada, porque sólo queda la base formada por el objeto y la palabra en una relación que se va extendiendo a medida que la escritura se materializa y se acerca al objeto. Como representación del objeto y como configuración textual, la escritura es signo. Por su parte, esa entidad arquitectónica múltiple relatada en $L a$ rue Vilin es un referente complejo en su doble dimensión biográfica y sociológica. Y entre ambos estadios del proceso sígnico (o semiosis) se halla el espacio: el espacio es primero un referente, es $e l$ referente, la calle Vilin, el objeto en que el artista apoya el acto creador; pero tam-

3 No se olvide en cualquier caso la dimensión espacial adquirida por el efecto de metarrepresentación, que supondría efectivamente una trascendencia más allá de estos límites a través del cúmulo de estructuras topológicas generadas en el juego interno de la escritura. 
bién es signo, porque la escritura, al inscribirse y materializarse, se hace objeto a su vez. De este modo, el espacio se convierte en una dimensión polivalente que justifica quizá la extensa base de esa pirámide (truncada y sin embargo) cada vez más rica en posibilidades de articular un discurso con gran capacidad significante.

\section{Referencias bibliográficas}

Apollinaire, G. (1925). Calligrammes. París: Gallimard.

Bollnow, O. F. (1969). Hombre y espacio. Barcelona: Labor.

Butor, M. (1954). Passage de Milan. París: Minuit.

ENZENSBERGER, H. M. (1966). «Estructuras topológicas en la literatura moderna». Sur 300, 3-16.

Greimas, A. J.; Courtés, J. (1979). Sémiotique. Dictionnaire raisonné de la théorie du langage. París: Hachette.

Lessing, G. E. (1990). Laocoonte o sobre los límites de la pintura y de la poesia. Madrid: Tecnos.

LOTMAN, Y. M. (1982). Estructura del texto artístico. Madrid: Istmo.

MALlaRmé, S. (1970). Un coup de Dés jamais n'abolira le hasard. En Oeuvres Complétes. París: Gallimard.

Perec, G. (1965). Les Choses. París: Julliard. Trad. esp.: Barcelona: Seix Barral, 1967, y Anagrama, 1992.

- (1974a). Espèces d'espaces. París: Galilée.

- (1974b). Ulcérations. En La Bibliothèque Oulipienne. París: Ramsay.

- (1976). Alphabets. París: Galilée.

- (1977). La rue Vilin. En L'Humanité, 11 nov. Trad. esp.: SuplementosAnthropos 34, 87-90, 1992.

- (1978). La Vie mode d'emploi. París: Hachette. Trad. esp.: Barcelona: Anagrama, 1988.

- (1980). La Clôture et autres poémes. París: Hachette-POL.

- (1988). Métaux. París: Atelier RLD.

QUenEAU, R. (1961). Cent mille milliards de poèmes. París: Gallimard.

Ricardou, J. (1987-1990). «Éléments de Textique I, II, III, IV». Conséquences $10,11,12,13 / 14$.

Wittgenstein, L. (1989). Tractatus logico-philosophicus. Madrid: Alianza. 